\title{
Topology Optimization Design of Internal Reinforcements in a Sailing Dinghy
}

\author{
Antonio Mancuso $^{1}$, Antonio Saporito ${ }^{1}$, and Davide Tumino ${ }^{2(凶)}$ \\ 1 Dipartimento di Ingegneria, Università degli Studi di Palermo, Viale delle Scienze, \\ 90127 Palermo, Italy \\ 2 Facoltà di Ingegneria e Architettura, Università degli Studi di Enna Kore, Cittadella \\ Universitaria, 94100 Enna, Italy \\ davide.tumino@unikore.it
}

\begin{abstract}
In this paper, a novel approach has been followed based on FEM simulation and Topology Optimization tools to locate and model the reinforcements inside the hull of a sailing dinghy. This process assumes that the inner volume included between the hull and the deck is, at the beginning of the simulation, filled with material; then a portion of this inner volume is eroded until a final free form shape of the reinforcements is obtained. A key point of this procedure is the definition of the optimization constrains because the final shape of the reinforcements must fulfill several requirements such as weight, stiffness and stress. At the end of the optimization procedure, the final shape of internal reinforcements consists of a truss-like web frame with a final weight equal to the $18 \%$ of the initial full body.
\end{abstract}

Keywords: Yacht design $\cdot$ Reinforcement $\cdot$ Topology optimization

\section{Introduction}

The traditional design approach of a sailing yacht is standardized by the international Rules for Classification and Construction [1]. Scantling of the internal structure derives by parametric equations that return the number and the dimensions of longitudinal and transverse frames to be applied to the hull in order to improve its local and global stiffness. Once the operating category and the material of the boat have been decided, governing mathematic relations are mainly related to the waterline length of the hull.

The possibility of a scantling procedure different from [1] has not been systematically researched yet. This also happens because, in the naval field, safety reasons suggest to be conservative in terms of reinforcement element design and that traditional manufacturing techniques based on panels and beams bonding are still preferred. Topology Optimization (TO) techniques [2] allow more freedom to the designer because the optimal structure is obtained from an initial bounding box that is gradually eroded in order to retain the minimum volume, usually with the maximum stiffness. Few attempts can be found in literature where TO is applied in marine applications. In [3], fixed shape stiffeners have been internally distributed for the composite submarine sail structure using TO 
techniques. In [4] TO has been used to determine only primary reinforcements of a $46 \mathrm{~m}$ sailing yacht: only quasi-static rig and weight loads are considered and the TO procedure is conditioned by the interior layout design.

In the present paper, a procedure implementing FEM simulations and TO has been defined in order to place the reinforcements inside the hull of a sailing dinghy. Structural and harmonic analysis results are input data to search the optimal mass distribution inside the boat. A set of optimized shapes has been compared to a traditionally designed reinforcement layout. This innovative approach, supported by modern additive manufacturing technologies and by related process parameters optimization [5], could represent a more efficient naval design method.

\section{Methods}

TO consists in finding the optimal solid-void pattern of a material layout inside a bounding box representing the design domain once boundary conditions are defined. In typical TO software, the design domain is meshed in Finite Elements which density can vary between 0 and 1 . In this paper the TO package by ANSYS has been adopted. It is a density-based topology optimization tool that uses a Solid Isotropic Material with Penalty (SIMP) method to define pseudo-density of each finite element of the mesh during optimization [2]. The optimization of a general non convex problem is solved with a Sequential Convex Programming (SCP) strategy. With this approach the convex portions of the problem are handled exactly and efficiently, while non convex portions of the problem are modelled by convex functions that are (at least locally) accurate.

\section{Case Study}

The boat studied is the 4,6 m length sailing dinghy represented in Fig. 1. It is an R3 class boat that has participated to the inter-university 1001velaCup regattas since 2012 and has been refitted in 2015 to reduce the maximum beam and the total weight. The lightening process has involved the reduction of the internal reinforcements that, at a first stage of construction, were over dimensioned. The internal layout of longitudinal frames and transverse sections was suggested by a traditional hull panel subdivision approach given in [1]. In Fig. 1 a unique longitudinal frame element can be easily distinguished, while four transverse sections are located at variable intervals. Furthermore, one of these sections (under the mast) is not properly transverse but is symmetrically rotated. The material assumed for the boat manufacturing is marine plywood, with a density $\rho=$ $500 \mathrm{~kg} / \mathrm{m}^{3}$ and a Young modulus $E=8 \mathrm{GPa}$. Hull and deck are obtained with $16 \mathrm{~mm}$ thick panels, while reinforcements have a thickness that varies from a minimum of $12 \mathrm{~mm}$ to a maximum of $20 \mathrm{~mm}$. The boat weight is $87 \mathrm{~kg}$. 

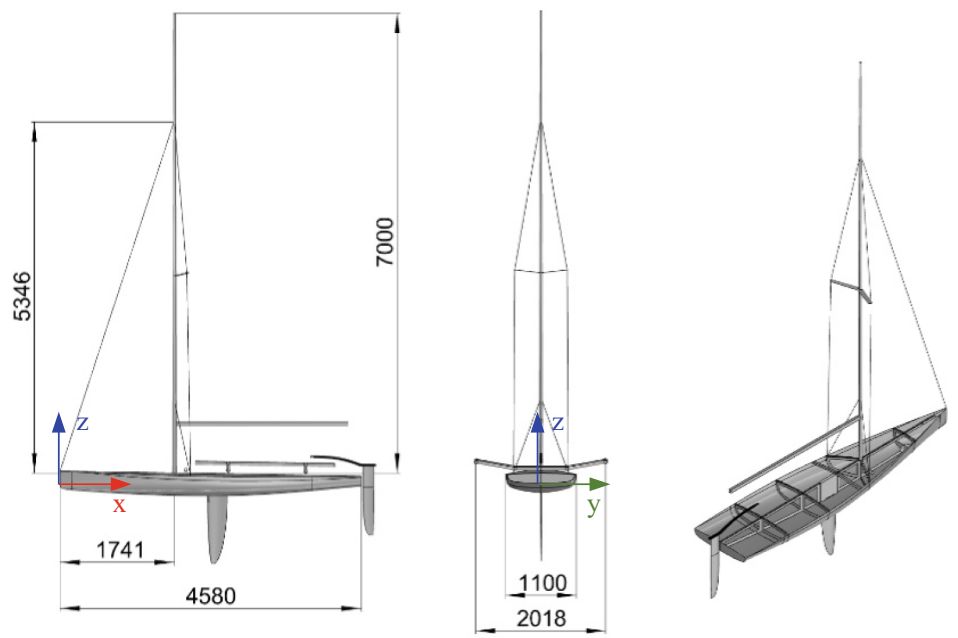

Fig. 1. View of the boat.

The original version of the boat has been numerically simulated with the Finite Element Method in order to obtain the deformed shape of the hull under navigation loads. The CAD model has been meshed into thick shell elements and a static structural analysis has been set up assuming that the boat is sailing beam reach with an Apparent Wind Speed of $6.4 \mathrm{~m} / \mathrm{s}$ and an Apparent Wind Angle of $45^{\circ}$. By using open source Velocity Prediction Programs, a drive force of $349 \mathrm{~N}$ and a heel force of $654 \mathrm{~N}$ have been calculated. The simplified method used in [6] has been here adopted to impose the equilibrium between the heeling moment given by the heel force and the maximum righting moment given by the crew members on trapeze in order to keep the boat flat on the sea.

Compressive preload is applied on the mast and traction preloads are applied on forestay and shrouds to return a self-equilibrated force system. External loads are superimposed to preloads when the boat navigates. Resulting force components are reported in Table 1. Preloads is a self-equilibrated force system, while the sum of external loads on the rig and on terrace equilibrates the heel and drive forces. The resultant force in the $z$ axis must be null. Loads have been applied on the FEM model of the original boat and displacement constraints have been added in the $z$ direction at the right ahead and at the stern to avoid undesired rigid body motion. At the trunk surfaces, a frictionless support is applied in the $x$ and the $y$ direction to simulate drag and lift actions given by the centerboard.

Results of a static structural analysis are then reported. In Fig. 2 it is evident that the critical portion of the hull is the one under the mast foot: compressive actions due to preload and to the crew weight on trapeze cause a maximum $z$ displacement of about $-1.2 \mathrm{~mm}$ and a distributed stress pattern over the rotated section with some local concentrations at the beam intersections.

TO of the boat internal reinforcement has been setup starting from a preliminary structural analysis of the full boat with loads in Table 1 applied on it and the same 
Table 1. Loads on the boat $[\mathrm{N}]$.

\begin{tabular}{l|l|l|l}
\hline Load & X component & Y component & Z component \\
\hline Preload port shroud & -107.5 & 177.35 & 2238.3 \\
\hline Preload starboard shroud & -107.5 & -177.35 & 2238.3 \\
\hline Preload mast & 0 & 0 & -5100 \\
\hline Preload forestay & 214.9 & 0 & 623.34 \\
\hline External port shroud & -19.346 & 31.927 & 402.94 \\
\hline External starboard shroud & 39.748 & 65.596 & -827.87 \\
\hline External mast & -260.62 & -410.61 & -1630.6 \\
\hline External forestay & 191.9 & 0 & 555.5 \\
\hline Terrace & -300.7 & -340.9 & 0 \\
\hline Displacement & - & - & 2364 \\
\hline Target weight & - & - & -873.5 \\
\hline Total & -349 & -654 & $\sim 0$ \\
\hline
\end{tabular}
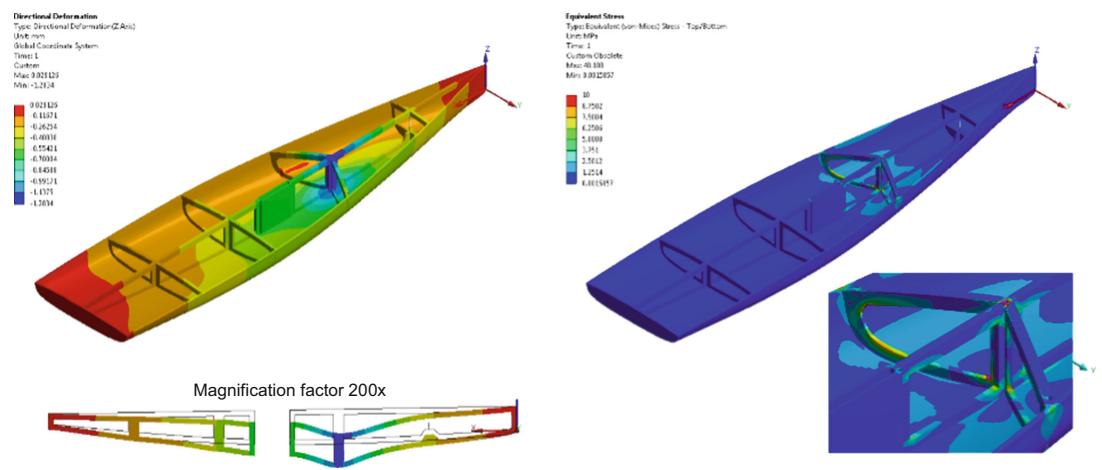

Fig. 2. FEM results on the original boat: displacement along $z$ and particular on the keel (left) and Von Mises stress on hull and reinforcements (right).

external constraints as the ones applied on the original boat. The only difference is that, in this case, the weight of the full boat is $445.4 \mathrm{~kg}$ because the volume between the deck and the hull is, at the beginning of the process, full of material. Volume is now meshed in solid hexagonal elements.

To perform the optimization procedure it has been considered that during navigation the boat can be also subjected to loads repeated at variable frequency, for example fluttering of sails or slamming caused by wave trains. These actions could interfere with natural frequency of thin hull panels and cause undesired resonance phenomena. The proposed TO procedure considers also the deformation caused by a modal analysis, then 
the optimization goal of the objective function is the research of this maximum value:

$$
\max (Z)=\max \left(w_{1} \mathrm{Obj}_{1}+w_{2} \mathrm{Obj}_{2}\right)
$$

where $O b j_{1}$ is the structure stiffness, $O b_{2}$ is the first harmonic frequency and $w_{1}$ and $w_{2}$ are relative weights varying between 0 and 1 , stepped by 0.25 .

Some response constraints have been added to all the analyzed cases: $z$ displacement of the keel line has been limited to a minimum of $-0.5 \mathrm{~mm}$, maximum Von Mises stress has been limited to $10 \mathrm{MPa}$ and the final mass must equal the original one, that is $87 \mathrm{~kg}$. Furthermore, some manufacturing response constraints have also been added: member mean dimension should be included between 15 and $300 \mathrm{~mm}$ and the retained volume must be symmetric with respect to the $x-z$ plane. Hull surfaces have been excluded from the optimization process.

\subsection{Discussion}

Results of the optimization process are reported in Fig. 3 for half boat (on the left) and for the transverse section under the mast foot (right).
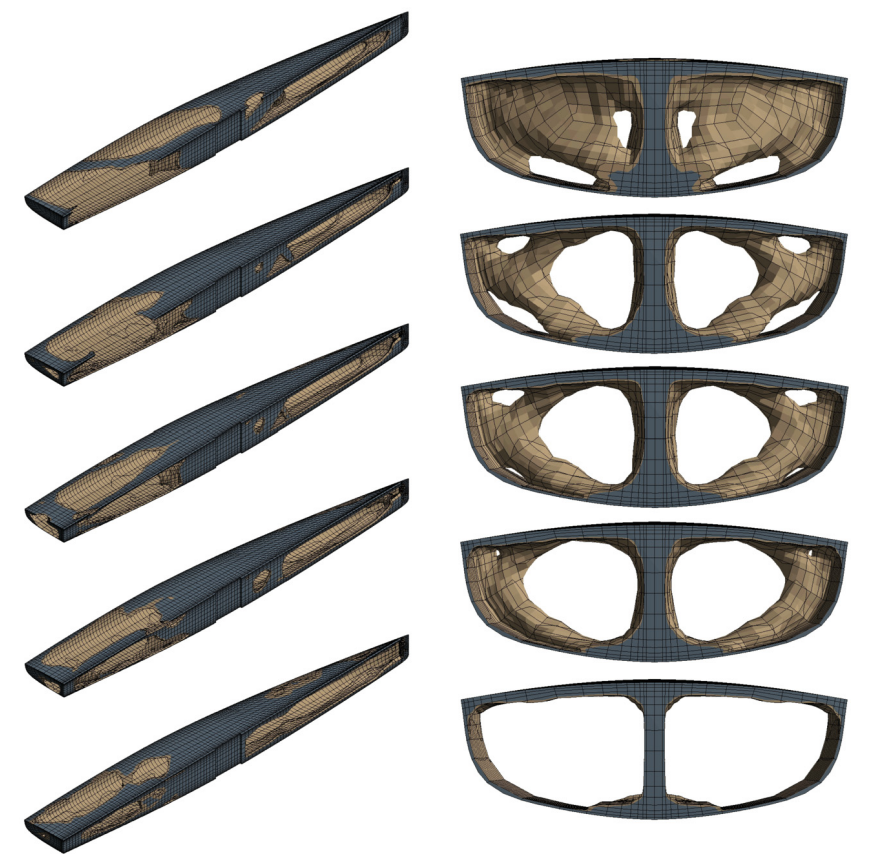

$\mathrm{O} 1$

$100 \%$ Structural

$0 \%$ Modal

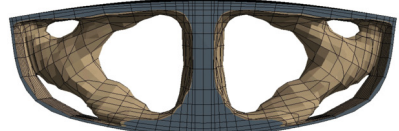

$\mathrm{O} 2$

$75 \%$ Structural

25\% Modal

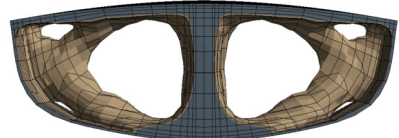

O3

$50 \%$ Structural $50 \%$ Modal

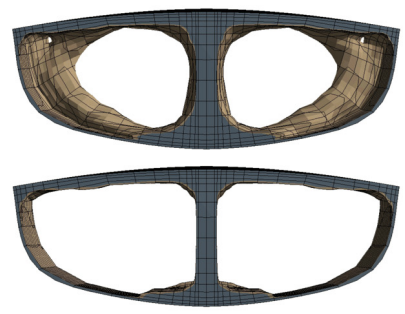

O4

$25 \%$ Structural $75 \%$ Modal

O5

$0 \%$ Structural

100\% Modal

Fig. 3. Topology optimized boat shapes: half volume (left) and central section (right)

The position of the center of gravity has been calculated and plotted in Fig. 4 left, together with the one calculated for the original boat. The coordinate $x_{\mathrm{CG}}$ affects the hydrostatic trim angle of the boat. The original boat has $x_{\mathrm{CG}}=2630 \mathrm{~mm}$ while for the 
optimized cases it varies between $2204 \mathrm{~mm}$ for $\mathrm{O} 1$ and $2770 \mathrm{~mm}$ for O5. As far as the structural component is reduced in favour of the modal component (from $\mathrm{O} 1$ to O5), $x_{\mathrm{CG}}$ moves towards the stern. To obtain the target original value of $x_{\mathrm{CG}}$, a correction mass should be properly located. The position of $z_{\mathrm{CG}}$ varies from a minimum of $67.75 \mathrm{~mm}$ to a maximum of $73.83 \mathrm{~mm}$. This parameter should be as lower as possible in order to improve the hydrostatic heel stability of the boat.

In Fig. 4 right is reported the relative reduction of each moment of inertia of the optimized boats with respect to the original one. The highest reduction can be observed for $I_{\mathrm{x}}$ (best is $32.69 \%$ saving for O2) while lower values are calculated for $I_{\mathrm{y}}$ (best is $14.16 \%$ saving for $\mathrm{O5}$ ) and for $I_{\mathrm{Z}}$ (best is $15.16 \%$ saving for $\mathrm{O} 5$ ).

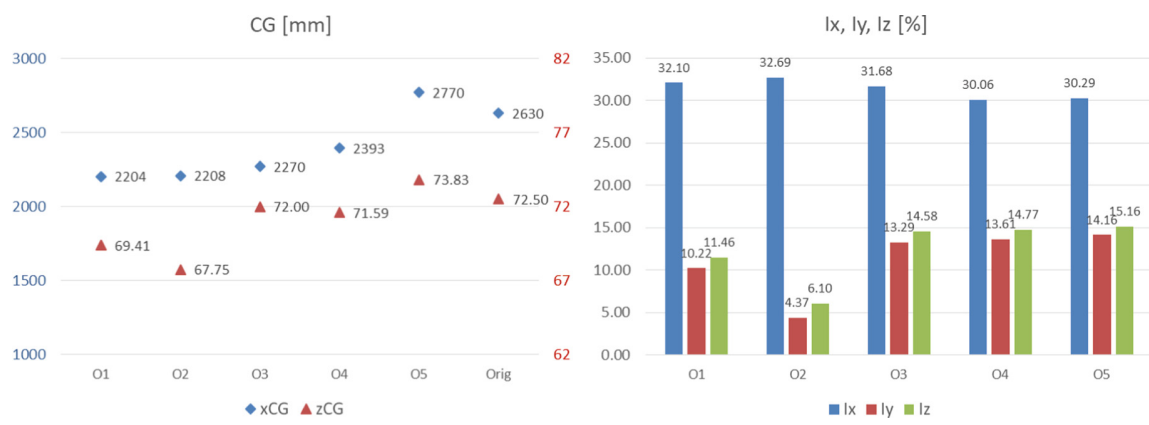

Fig. 4. Center of gravity position (left) and relative moment of inertia reduction (right).

\section{Conclusions}

A numerical procedure implementing FEM and TO has been defined in order to define a reinforcement layout inside the hull of a sailing dinghy. This must fulfill two concurrent objectives: maximum stiffness and highest natural frequency of the reinforced boat. Optimized shapes have been compared with traditionally designed reinforcement layout, keeping the same total weight. A consistent reduction in the moment of inertia has been obtained around the longitudinal axis (between $30 \%$ and 33\%) and around the transverse axis (between $4 \%$ and 14\%), meaning an improved maneuverability and sea-keeping attitude. Moreover, the optimized shapes exhibit more regular vertical deflections of the keel under static loads. In the authors' intentions, the obtained TO CAD shape should be step-wise approximated and realized by overlapping constant thickness layers of marine plywood inside the hull.

\section{References}

1. ISO 12215-5n Small craft - Hull construction and scantlings - Part 5

2. Zhang, W., Zhu, J., Gao, T.: Topology Optimization in Engineering Structure Design. ISTE Press Ltd. (2016) 
3. Rais-Rohani, M., Lokits, J.: Reinforcement layout and sizing optimization of composite submarine sail structures. Struct. Multidisc. Optim. 34, 75-90 (2007)

4. Leidenfrost, D.: Development of a Nature Inspired Hull Structure for a 46m Sailing Yacht, Master thesis, 2015. Hochschule Bremen, Dykstra Naval Architects, Alfred-Wegener-Institut.

5. Ingrassia, T., Nigrelli, V., Ricotta, V., Tartamella, C.: Process parameters influence in additive manufacturing. In: Lecture Notes in Mechanical Engineering, pp. 261-270 (2017)

6. Mancuso, A., Pitarresi, G., Tumino, D.: Using FEM simulation to predict structural performances of a sailing dinghy. Int. J. Interact. Des. Manuf. 12, 811-822 (2018)

Open Access This chapter is licensed under the terms of the Creative Commons Attribution 4.0 International License (http://creativecommons.org/licenses/by/4.0/), which permits use, sharing, adaptation, distribution and reproduction in any medium or format, as long as you give appropriate credit to the original author(s) and the source, provide a link to the Creative Commons license and indicate if changes were made.

The images or other third party material in this chapter are included in the chapter's Creative Commons license, unless indicated otherwise in a credit line to the material. If material is not included in the chapter's Creative Commons license and your intended use is not permitted by statutory regulation or exceeds the permitted use, you will need to obtain permission directly from the copyright holder.

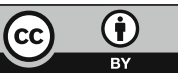

